\title{
La Diversidad cultural En la era de la globalización**
}

\section{Edgar Montiel ${ }^{*}$}

Como se sabe, el concepto es una manifestación teórica de la realidad. Globalización y mundialización son conceptos en proceso de definir los ámbitos de la realidad que buscan expresar, más allá de las percepciones periodísticas y que están en uso desde hace más de dos décadas en el ámbito público y académico. Estos conceptos representan, a la vez, un sintoma y una manifestación fundamental del cambio cultural, económico y tecnológico contemporáneos, y constituyen las principales imágenes de transformación del mundo de hoy.

Diversos intelectuales que han abordado el tema, como Alain Touraine, lo advierten: la llamada globalización es un fenómeno parcial que no se extiende a todos los ámbitos de la actividad humana.

Se observa que si bien hay una rápida circulación financiera de capitales internacionales y un impetuoso movimiento de estandarización simbólica - ambos debido a las nuevas tecnologias de la información -, la globalización de las economías no tiene el mismo impulso, ya que la mayor parte de las economías de los países se continúan realizando dentro

* Tomado de Hacia una mundialización humanista Serie Cultura y Desarrollo, Publicaciones UNESCO. Paris, 2002

-El autor agradece la valiosa colaboración de Gregorio Recondo, sociólogo de la cultura; Patricio Dobree, investigador en comunicación; y Katerina Stenou, directora de la División de Politicas Culturales de la UNESCO, en la elaboración de este estudio. de sus propios límites territoriales o, a lo sumo, en tres bloques: Norteamérica, Asia y Europa, el triángulo mayor del comercio internacional. Aldo Ferrer recuerda que nueve de cada diez productos nacionales se destinan al mercado local, y que América Latina ha descendido su participación en el comercio mundial de $9 \%$ en 1950, a $4,5 \%$ en 2001.

Asistimos, sin embargo, a un replanteo civilizatorio que nos afecta a todos. Una de las características más visibles y trascendentes de la mundialización la constituye el surgimiento de una cultura global inédita, de un magma pluricultural generado por las nuevas tecnologías de la información y las comunicaciones, que da lugar a nuevas dinámicas, procesos y escenarios culturales. En ese contexto, ¿cuáles serían los principios básicos que deberían tenerse en cuenta para la elaboración de una nueva ética global, respetuosa de la diversidad cultural en este siglo que recién ha comenzado?.

Después de la Segunda Guerra Mundial, la humanidad ha sido testigo de transformaciones en el dominio de la ciencia y la tecnologia que han configurado de nuevo el espectro económico, social y cultural de casi todas las comunidades del orbe. Entre los numerosos y vertiginosos avances que ha dado a luz la ciencia modema, quizás uno de los más notorios e influyentes haya sido el de las nuevas tecnologías de la información y las comunicaciones. 
El gigantesco desarrollo de las industrias de la información, de las telecomunicaciones y del audiovisual, potenciadas ahora por la revolución digital, ha provocado transformaciones estructurales en las sociedades actuales, y dado lugar a nuevas formas de experiencia humana.

Nos encontramos frente a un cambio cultural que significa un cambio de época (1). Asistimos al nacimiento de la sociedad de la información, caracterizada por una inundación de datos y una globalización de simbolos que circuIan libremente sin un referente territorial definido. Es pertinente destacar que, entre las innovaciones causantes de la globalización - la robótica, la biotecnologia, la temática -, la informática y las tecnologias de la comunicación son las que más se has socializado, tanto en el ámbito empresarial como popular, en tanto medios eficaces para globalizar el mercado y el consumo.

Como resultado de la facilidad con que se produce los intercambios, hoy en dia el acceso a los bienes culturales electrónicos se ha modificado: las imágenes emitidas pierden muchas veces los rasgos que antes servian para identificarlos con una nación o una comunidad determinada. Las culturas de los diferentes paises experimentan procesos de hibridación; la cultura comunitaria y la cultura de masas se mezclan y generan nuevas formas de creación y consumo. Un ejemplo ilustrativo de este fenómeno lo constituye cualquiera puesto callejero de venta de revistas. Alli podemos encontrar todo tipo de referencias culturales; desde el último ejemplar de Nacional Geographic o Vanidades hasta el Ulises de James Joyce, la colección de discos compactos de Ricky Martin, un póster de Póckemon o un video de las obras de Goya expuestas en el Museo de Prado.

Pareciera que viniéramos en un mundo desbordante de cultura, donde las realizaciones del espiritu humano están dispuestas en un gran escaparate para ser consumidas por cualquiera, en cualquier momento.

El flujo de símbolos circulantes estaría haciendo realidad recién hoy la "aldea global" imaginada por el sociólogo canadiense Marshall McLuhan, sin fronteras y en permanente expansión gracias a las tecnología.

(1) Tomassini, Luciano 2000 . "El giro cultural de nuestro tiempo", en B Kliksberg y L. Tomasini, eds. Captal social y cultural claves estratégicas para ei desarro fio BID / FCE / Fundación F Herrera / Universidad de Maryland, Buenos Aires.
Como consecuencia de la planetización tecnológica de las comunicaciones, tenemos la ilusión de ser herederos y legatarios de todas las culturas y dueños "virtuales" de todos los paisajes, de todas las obras maestras de la pintura y de la música...

Al hablar de derechos culturales, esta complejidad se evidencia con mayor fuerza. El artículo 27 de la Declaración Universal de los Derechos Humanos establece el derecho al acceso a la propia cultura y al patrimonio cultural de otros. La participación de cada individuo en la cultura significa tanto elegir libremente los elementos tradicionales de su cultura - el teatro, el cine, la música, las danzas, los ritos -, como el derecho de hablar su propia lengua, a beneficiarse del progreso científico y tecnológico y, en líneas generales, a la educación. ¿En qué medida la globalización facilita el ejercicio de tales derechos y en qué medida los obstaculiza? Esa es la pregunta imperativa que nos proponemos abordar.

\section{EI Problema de la estandarización simbólica}

Una de las características que más resaltan de los habitantes de cualquier ciudad del mundo es su tendencia a parecerse cada vez más en lo que respecta a sus costumbres, gustos, ideas y hábitos de consumo. Las personas tienden a identificarse con los mismos símbolos, tanto en Buenos Aires como en Miami. El hombre contemporáneo podría ser definido como logófago, es decir, como un devorador compulsivo de símbolos. Como resultado, el imaginario colectivo de las sociedades se va articulando en función de lugares, estéticas, programas de televisión, marcas de productos, lecturas, modos entre tantas otras formas simbólicas que responden a un denominador común.

La masificación simbólica nace a partir de la necesidad de las industrias culturales en plena expansión, de crear mercados globales donde colocar sus productos. Es necesario reconocer que este proceso de transculturación generada por la globalización no se da sin intercambios mutuos entre las diferentes culturas. Por un lado, las empresas transnacionales están 
obligadas a reconocer "algo" del carácter local de los paises donde insertan sus productos. Por otro, la masa de inmigrantes en los paises del primer mundo logra que se vayan incorporando un poco algunos de sus elementos culturales.

Sin embargo, no se pueden pasar por alto los indicadores que muestran las asimetrias existentes entre las sociedades del Norte y del Sur. Entre 1975 y 1991, 68,5\% de los bienes culturales exportados correspondieron a los paises desarrollados, que sólo representan $23 \%$ de la población mundial. Por su parte, los paises en desarrollo sólo exportaron $31.8 \%$ de los bienes culturales, mientras que representan $77 \%$ de la población mundial (2). Otros ejemplos de esta desigualdad tienen lugar en el campo audiovisual e informático. La oferta de películas en los videoclubes latinoamericanos está compuesta en un $70 \%$ a $30 \%$ es cine norteamericano (3). Asi mismo el $70 \%$ de los sitios web que actualmente se encuentran en internet son de origen estadounidense (4).

Para abarcar la mayor cantidad de consumidores, y de este modo lograr altas tasas de beneficio, las industrias culturales de los centros hegemónicos tienden a homologar lenguajes, haciendo accesibles sus productos a una pluralidad de públicos. Los significantes, asi, se vacian de contenido específico; la necesidad de hacer accesible el mensaje a todos hace que no se diga nada especifico a nadie.

El mercado tiene a su cargo el impulso para regular las relaciones entre nacionales y culturas, impone los modelos de comunicación y organiza las respectivas redes. Nuestro planeta vive un proceso expansivo de fragmentación, dice Martin Barbero. El reconocimiento de su conciencia parece desembocar en la manera de relativizar toda certeza e inclusive "en la negación de cualquier tipo de comunidad y aun de sociabilidad" (5). Ante esta realidad, ¿qué posibilida-

(2) UNESCO, 1997 Nuestra diversidad creativa Informe de la Comision Mundial de Cultura y Desarrolio. Ediciones UNESCO. Madrid

(3) Garcia Canclini, Nestor 1995 Consumidores y ciudadanos Conflictos muitculturates en la era de la globahización. Grijalbo, Mexico. DF

(4) UNESCO 2000 Revista Fuentes, n 119. Paris, Enero des tiene un individuo o grupo humano de ejercer su derecho a elegir su propia cultura? Uno de los requisitos básicos para elegir con libertad consiste contar con variedad de opciones. Si la cultura que se ofrece es una sola, esa elección pierde su valor.

El desarrollo de una cultura de masas estandarizadas, que adquiere gran poder gracias al uso de las nuevas tecnologías de la comunicación y la informática, trae aparejado el riesgo de que queden al margen los gustos e intereses de las minorias culturales. Por estas entendemos tanto a las culturas de los paises menos desarrollados como las culturas de los grupos no hegemónicos dentro de cada sociedad. Ignorar las culturas minoritarias significaria sumirlas en el olvido, y privar a sus miembros de elaborar una propia construcción del mundo, su propia cosmovisión. La vida humana está hecha de significados, y ello implica libertad para decidir que valores afirmar. Por eso la problemática cultural no puede ser abordada desde una perspectiva puramente de mercado. Como anota Fernando Savater, " a la cultura no es algo que consumir, sino que asumir. $Y$ no se puede asumir la cultura, ni precavernos de quienes quieren convertirla en pura mercancía si se la desliga totalmente del trabajo creado que la produce" (6) En caso contrario, el individuo ya no se relatará a si mismo en forma autónoma, sino que será relatado por otros con mayor poder.

\section{La identidad en su laberinto}

La cultura es uno de los elementos fundamentales para la constitución de la identidad de un pueblo. En nuestra América, el sentimiento de lealtad y pertenencia a una nacionalidad anida en el inconsciente colectivo, muy dificil de desarraigar, y se ha mostrado irreductible a las influencias de la publicidad comercial y la propaganda política. 
La creciente estandarización de símbolos podría conducir a una disolución de las identidades. Frente a este fenómeno, numerosos grupos humanos no han permanecido indiferentes. El acecho de manifestaciones culturales ajenas a las propias ha generado reacciones alérgicas en grupos que tienden a encerrarse en si mismos. En algunas naciones del Medio Oriente se ha prohibido la difusión de programas de televisión occidentales. No son mera coincidencia los rebrotes de xenofobia y racismo que se ven en las calles o en las canchas de fútbol de muchos países. Como contrapartida al rigido discurso nacionalista - xenófobo, los pueblos del Sur padecen el trepidar, incesante de mensajes emitidos por los medios, incitándoles a la "libre elección" de productos que deben consumirse de manera compulsiva.

Observamos con temor el surgir de lo que Kart Popper definió como "sociedades cerradas", caracterizadas por ser acríticas, totalitarias y expuestas a arbitrariedades. En este tipo de sociedades, la fijación de una identidad de grupos estática conduce a la exclusión de los grupos minoritarios que no se ajustan a ella y a la negación de la posibilidad de un diálogo enriquecedor con otras culturas.

Como se sabe, pretender fijar una identidad monolítica, invariable al paso del tiempo, definida por una esencia de una vez y para siempre, es una ilusión. Las culturas adquieren vitalidad a través de préstamos mutuos, de procesos interculturales en los que convergen fuerzas desde distintos centros. No es la primera vez que la humanidad ha experimentado una globalización. Ha ocurrido durante distintos periodos históricos. Recordemos los casos del helenismo, el Imperio romano o el descubrimiento de América, por sólo mencionar algunos.

Hombres provenientes de diferentes tradiciones culturales han intercambiado saberes, bienes y costumbres, condicionándose y enriqueciéndose mutuamente. Por eso, la pretensión de algunos de aferrarse a lo originario, a lo que define la esencia primordial de su grupo, constituye en cierta medida un proyecto fútil visto en el largo plazo. ¿Qué es lo originario para nuestros paises? ¿EI "ser nacional" propuesto por las protoburguesias a comienzos del siglo?
¿El criollo de la colonia? ¿El autóctono precolombino? ¿El hombre ancestral que ingresó al continente americano por el estrecho de $\mathrm{Be}$ ring? Toda identidad es acumulativa, se sedimenta, cambia y se renueva. Para la conciencia colectiva importan las tradiciones que permanecen y las innovaciones que cuentan con arraigo. Las identidades son relatos construidos a lo largo de la historia; formas en constante devenir de imaginarnos y reinventarnos. Se puede considerar que "la identidad (...) no será sólo una narración ritualizada, la repetición monótona pretendida por lo fundamentalismos. Al ser un relato que reconstruimos incesantemente, que reconstruimos con los otros, la identidad es también una coproducción (...) La identidad es teatro y es política, es actuación y acción".

Salvo eventuales derivas esencialistas, la identidad cultural manifiesta un ethos afirmativo, de continuidad, no obstante las mutaciones. $Y$ frente a los embates globalizadotes, reacciona reclamando derechos vulnerados. Observa Edgar Morín que al desafío de la planetización homogénea (challenger) se pone la defensa de las identidades (reponse). Se trata de una propuesta de vida, que se muda en el tiempo y produce sucesivas identificaciones. Está claro que no hay lealtades únicas, sino pertenencias múltiples. La identidad es un plebiscito que se construye diariamente. En la dialéctica entre tradición y modernidad se expresaria una síntesis consistente en conservar lo vivo y transformar lo que declina.

Tomando la idea del individuo como actor, como responsable de su ser, volvemos al tema de los derechos culturales. Si la identidad es construcción, la interrogante es cómo llevamos a cabo esta tarea. Podríamos hacerlo, por un lado, bajo la tutela de un grupo dominante que nos impone un modo único y cerrado de ser según lo que este cree que define la esencia de la cultura propia, configurada por rasgos nacionales, étnicos o religiosos.

Podríamos adoptar, por otro, una actitud receptora pasiva, permeable a la avalancha de símbolos y mensajes globalizados producidos por las industrias culturales hegemónicas que buscan ganar mercado. $Y$ también podriamos avanzar de otra manera, patrocinada por la filosofía posmoderna, que consiste en negar el 
concepto o la importancia de la identidad. Si el "metamensaje" consiste en atentar contra cualquier cosa que defienda las particularidades nacionales, se facilita la acción del mercado, que ya no tendrá obstáculos para aplicar su filosofía fundamentalista.

Pero ninguna de estas tres formas de concebir la creación de identidad respeta la noción de derechos culturales. La constitución de la identidad debe ser un acto de elaboración propia. Cada comunidad tiene el derecho de construir su identidad de un modo autónomo, libre y creativo, en función de sus propios intereses y en relación con su propia historia, con su propio proyecto de vida en común. Esta construcción, amén de suponer la defensa y apuntalamiento de lo propio, tiene que ser abierta , tolerante, beneficiarse con los aportes de otras culturas y hacer respetar su derecho a la diferencia.

\section{Geopolítica de las lenguas}

Actualmente se hablan en el mundo cerca de seis mil lenguas y cada mes "muere" una de ellas (7). Según los estudios lingüísticos, alrededor de $90 \%$ de las lenguas hoy habladas dejarán de existir en este siglo. Esta pérdida encuentra sus causas fundamentales en la falta de hablantes jóvenes y en los beneficios que hallan los hablantes al adoptar las lenguas de los centros económicos más poderosos. Los grandes productores de bienes culturales, como yacimos, estimulan esta tendencia porque la homogeneización de códigos resulta más provechosa para alcanzar audiencias más amplias de consumidores.

Del mismo modo en que los humanos hemos tomado conciencia de la necesidad de conservar la biodiversidad en nuestro planeta, ahora debemos actuar para evitar que se extingan las lenguas. La lengua escrita y halada de un pueblo es tal vez su atributo cultural más importante, teniendo en cuenta que representa un modo de comprender el mundo, una manera de estar en el tiempo, una forma de resolver sus problemas. Mediante el lenguaje nombramos las cosas que encontramos en el mundo, $y$ asi le otorgamos un valor.

(7) UNESCO, 2000 Revista Fuentes, n. 122, Paris, abril
Cuando una lengua muere, muchos objetos, ideas o valores quedan sin nombre y mueren con ella. De este modo, la humanidad empobrece el horizonte de su patrimonio. El hecho de abandonar una lengua y adoptar otra diferente implica, de algún modo, una desvalorización de la propia forma de ser del individuo y de la comunidad donde está inserto. Cuando la lengua deja de ser un medio para reconocerse, entonces se comienza a pensar que la realidad está en otra parte, y este efecto no hace más que subordinar una cultura a otra potencialmente más fuerte.

Cada individuo o grupo tiene derecho a comunicarse en su propia lengua. Nadie puede privarlos de la libertad de relatar su experiencia humana haciendo uso de sus propios códigos para definir sus creencias, hábitos e ideas rectoras. El filósofo venezolano Ernesto Mays Ballenilla defiende este derecho diciendo:

Limitar, cortar o prohibirle a una persona el derecho de aprender escolarmente la propia lengua dentro de cuyo ámbito ha nacido - tal como lo estamos presenciando, no sin asombro ni perplejidad, en algunas regiones del mundo civilizado - es cercenar y no respetar la dignidad de esa persona como tal y, en el fondo, un manifiesto interno de poner en práctica un indefinible y anacrónico genocidio lingüístico. $A$ través de la lengua y sus meandros etnológicos se adquieren la educación y la cultura, bases primordiales de la propia idea del hombre y el mundo que cada cual se forje (8).

La valoración de las lenguas naturales lleva, precisamente, a apreciar y a aprender las otras lenguas, que es una forma de entrar a otros mundos culturales, lo cual fortalece profundamente la convivencia fraterna y útil.

El escritor Uslar Pietri decía que nuestros paises hispanoamericanos son las repúblicas de Cervantes, ya que los "hispanos" nos identificamos y reconocimos a nosotros mismos por el idioma que hablamos. La lengua es el instrumento vincular más poderoso en la construcción de nuestra comunidad cultural.

(8) Mayor, Federico 1998 comp., Los derechos humanos en el siglo XXI, Ediciones UNESCO, Barcelona. 


\section{El falso dilema entre cultura y desarrollo}

Algunos consideran que la multiplicidad de culturas representa uno de los grandes desafios para la políticas de desarrollo y modernización: Cuando se reflexiona acerca de las causas que impiden a los paises menos favorecidos salir de la pobreza e iniciar una etapa de crecimiento, se suelen mencionar las "trabas culturales" que los mantienen en el atraso. Estiman que la idiosincrasia de un pueblo constituye una especie de barrera intangible que reduce las posibilidades de desarrollo económico. Se impone entonces una polarización radical entre los conceptos de "tradición" y "modernidad", que leva a un enfrentamiento estéril. Esta percepción no se comprueba históricamente. Se pueden ver paises que han encontrado sus propias vias de modernización y desarrollo: desde la diversidad, paises como Estados Unidos y Suiza; y desde tradiciones arraigadas, Japón y Francia.

Para distinguir mejor algunos aspectos, la globalización conlleva, a veces, la difusión de modelos de crecimiento incompatibles con ciertas pautas culturales. Esta situación genera desencuentros con las mentalidades, las costumbres, los hábitos de trabajo y de consumo, los modos de relacionarse con la tierra; es decir, con la cultura de determinados grupos sociales.

Es necesario comprender que los modelos de desarrollo no pueden ser mecánicamente aplicables a cualquier medio, sino que deben ser adaptables a cualquier medio, sino que deben ser adaptables a sus bases culturales en un proceso gradual. El desarrollo no es un concepto pret-a-porter.

Encerrarse en determinadas tradiciones rigidas tampoco es beneficioso para ninguna sociedad. No se puede condenar a un grupo humano, por una suerte de determinismo, a permanecer en niveles de escaso desarrollo, sin acceso a los avances que ha producido la humanidad en los últimos tiempos. Como ha recordado Alain Touraine, "el individuo es el actor. $Y$ precisamente en el individuo (que también puede ser colectivo) se debe realizar esta conciliación, esta complementariedad, entre la racionalidad - que es participar en la economía y la tecnología -, y la cultura, que no es solamente herencia, sino también imaginación"(9).

Como hemos señalado, la cultura está en permanente construcción, es creatividad para producir nuevas formas; los miembros del cuerpo social participan de esta creación colectiva. Resulta imperioso, por lo tanto, armonizar la racionalidad de un desarrollo durable con las formas de la cultura de un pueblo Ambas no se excluyen.

Desde la perspectiva de los derechos humanos, también observamos esta necesidad de complementariedad. Como se sabe, los derechos culturales se encuentran agrupados en la Declaración Universal de los Derechos Humanos, junto con los derechos sociales y económicos. Los derechos humanos no pueden ser excluyentes, sino inclusivos; es decir, la afirmación de un derecho no puede redundar en la negación de otro. Es consecuencia, el valor implicito de los derechos culturales no pueden contradecir el derecho de las personas y de los grupos a tener un trabajo, un nivel de vida adecuado, los beneficios de la seguridad social o la educación. "Cultura" y "condiciones de vida dignas" deben ser términos complementarios en toda sociedad.

\section{Elementos fundamentales para una nueva ética global en el siglo XXI}

En el plexo de la cultura está la ética, que aporta visiones valorizadas y le da sentido al mundo simbólico que instruye en el modo de ser y la conducta de personas, grupos y sociedades. En 1993, Alpha Oumar Konaré, presidente de la República de Mali, expresó una idea que resume la esencia de una nueva ética global en materia de cultura para este siglo: "Mientras una civilización ejerza sobre otras una presión política, intelectual y moral, basada en aquello que la naturaleza y la historia le han concedido, no podrá haber esperanzas de paz para la humanidad: la negación de las características específicas culturales de un pueblo equivale a la negación de su dignidad" (10). Está muy claro. No habrá nunca paz social duradera mientras subsistan resabios de colonia(9)Touraine, Alain 2000 "Texto inédito de la reunión con miembros de la clase politica del Paraguay", UNESCO. Asunción, abril. (10)UNESCO. Nuestra diversidad creativa, $O b$. cit 
lismo cultural o de uso unilateral de la fuerza, por una parte, y asedios uniformizantes contra la diversidad cultural, por otra.

El derecho de cada grupo humano a elegir y asumir su propia cultura es un compromiso que debe ser respetado a escala planetaria. Hoy, más que nunca, vivimos en un mundo "conectado" entre si donde cada acción repercute en varios planos. Es necesario, por lo tanto, que todas las instancias de las diferentes sociedades sepan respetar y defender determinados principios básicos que garanticen este derecho. Concordante con la realidad mundial, una nueva ética global que actúe como marco para el ejercicio de los derechos culturales deberá estar definida por los siguientes objetivos.

\section{Defensa del pluralismo}

La diversidad y pluralidad de culturas deben ser permanentemente afirmadas y estimuladas en todo el mundo. Cada cultura representa un valioso tesoro para la humanidad. La pérdida de cualquiera de ellas significa un empobrecimiento del horizonte humano. El valor de la diversidad reside en la capacidad que tiene cada cultura de abrir nuevas perspectivas y aportar nuevos elementos que enriquecen la experiencia y la sabiduría humanas.

Como ejemplo de esta extraordinaria capacidad, hacemos referencia a un caso que cita Ernest Cassier en su Antropología filosófica: (11) el gran desarrollo del álgebra en Babilonia se debió al encuentro y el esfuerzo por comprenderse de dos culturas diferentes. Los sumerios y acadios fueron razas de origen diverso, que hablaban lenguajes sin ninguna relación entre sí. Cuarido estos dos pueblos se juntaron y tuvieron que participar de una vida política, social y cultural común, debieron resolver problemas nuevos, y para su solución tuvieron la necesidad de desarrollo nuevos recursos intelectuales. Gracias a este esfuerzo de comprensión mutua, los babilonios fueron los primeros en desarrollar el simbolismo abstracto.

Ejemplos como este abundan a lo largo de toda la historia de la humanidad. La diferencia no puede ser interpretada como algo extraño o inaceptable, sino como una forma de coexistencia con los (11)Cassier, Ernest 1979 Antropologia filosofica. Fondo de Cultura Económica, Mexico, DF. demás, de la cual podemos aprender e intercambiar conocimientos valiosos. Sin la diferencia, el crecimiento humano seria prácticamente imposible. Cuando el diálogo intercultural nos ayuda a entender al otro, y de este modo asimilar su manera singular de interpretar el mundo, la humanidad realiza sus más grandes progresos.

Es pertinente, de igual manera, tener en cuenta que "la diversidad cultural es diferente y desigual porque las distintas instancias e instituciones que la construyen tienen distintas posiciones de poder y legitimidad". Hay fuertes y débiles; consorcios transnacionales y gobiernos nacionales, etc. El proceso de globalización potencia las diferencias culturales, por lo que muchas veces aviva las manifestaciones de identidad, empujándolas hacia manifestaciones de esencia. El investigador Ricardo Ortiz nos alerta para superar la confusión de que "nuestro mundo es múltiple y plural"(12).

Según esta idea, diferenciación es igual a pluralismo (y ambos, sinónimos de democracia). Se trata de una falsedad histórica. La diferenciación - nos dice - es intrínseca a la modernidad y la diversidad existe desde siempre. Las "diferencias" también esconden relaciones de poder; el discurso sobre la diversidad oculta, a veces, cuestiones como la desigualdad. "No, diferencia no es igual a pluralismo" (13).

\section{Tolerancia y respeto}

Las culturas no son mensurables en términos de una jerarquia, donde algunas aparecen más valiosas o importantes que otras. Todas las culturas tienen dignidad. Cada cultura es un fin en si mismo que otorga sentido a la vida de las personas participando de ella. Muchos de los conflictos que han acabado con millones de vidas humanas durante el siglo pasado, se han originado en el sentimiento de superioridad que algunos grupos han sentido respecto a otros.

El holocausto de la Segunda Guerra Mundial, los combates constantes en el Medio Oriente, las sangrientas matanzas en Ruanda, la devastación de pueblos enteros en la antigua Yugoslavia,

\footnotetext{
(12) Ortiz, Ricardo 2002 "Diversidad cultural y universalidad", en Cultura y globalización, Paidós, Buenos Aires,

(13) Ibidem. Véase también, del mismo autor, Mundialización y cultura, Alianza Editorial, Buenos Aires.
} 
tuvieron lugar debido a la incomprensión mutua de pueblos diferentes, incapaces de dialogar entre sí. Lamentablemente, los ejemplos continúan repitiéndose y observamos con preocupación que la fuer$z a$ es ejercida unilateralmente y sin consenso internacional por las potencias hegemónicas. Esto se suma a la saturación del universo simbólico con una cultura de la violencia, machismo, muerte, fratricidio, xenofobia y arbitrariedad como espectáculo que promueve, en lo esencial, el cine, la TV y los juegos electrónicos infantiles. La violencia vende, $y$ esta es la ley del mercado.

Uno de los principales desafíos a enfrentar, en estas circunstancias, es la instauración de los valores de tolerancia y respeto. EI permanente flujo de personas y símbolos existentes en la actualidad hace que cada día tengamos mayor contacto con culturas diferentes que nos interrogan con su modo particular de ser. La respuesta a estos estímulos no puede ser la del rechazo y la violencia, sino que debemos celebrar esta diferencia que permite mirarnos en el espejo. La tolerancia y el respeto mutuo son las vias que nos conducirán a un ejercicio efectivo de los derechos culturales.

\section{Democratización de la cultura}

La participación de las personas en los sistemas culturales del siglo recién comenzado es un derecho que también tiene que ser reivindicado a través del paradigma de la democracia cultural. Como hemos visto, el dominio de las tecnologías de la información y las comunicaciones por parte de grupos hegemónicos tiende a desplazar de la escena a minorías culturales que no tienen posibilidades de manifestarse. Sus voces quedan apagadas y se transforman en receptores pasivos de mensajes ajenos.

La democracia cultural significa dar participación y representación a la gran variedad de personas y grupos culturales existentes, asi como potestad para intervenir en la toma de decisiones en cuanto les atañe. Este principio debe regir tanto a escala mundial como dentro de cada sociedad en particular. Cada comunidad cuenta con una gran variedad de grupos culturales en plena actividad, sean niños, jóvenes, mujeres, miembros de la distintas clases sociales, inmigrantes, indigenas, personas con diferentes opciones sexuales, etcétera.
Muchas veces un sector predominante tiende a imponerse sobre los demás, cercenando la libertad de elegir y manifestarse de los más débiles. En el contexto de una nueva ética mundial, esta clase de imposiciones debe ser rechazada. Cada persona y cada grupo poseen el derecho a disfrutar de su propia cultura, profesar la propia religión, utilizar la propia lengua, formar sus propias asociaciones y definir su propio estilo de vida. El marco para el ejercicio de estas libertades tiene que ser el de la convivencia democrática entre actores diferentes, pero con las mismas oportunidades.

\section{Ejercicio de la creatividad}

Una cultura estática e inmutable que no se renueva a si misma puede convertirse en una de las mayores fuentes de opresión para el ser humano. El hombre es un eterno insatisfecho que tiene la necesidad permanente de reinventarse. Un medio que no le brinde el espacio para desarrollar nuevas ideas, para proponer nuevos horizontes de realización, termina asfixiándolo. Por eso la identidad cultural no debe convertirse en un concepto cerrado a nuevas formas de expresión. Muchas sociedades resistentes al cambio han terminado destruyéndose por la ausencia de soluciones creativas a sus problemas.

La creatividad es un bien intangible al que tiene derecho todo individuo o grupo humano, sin distinción de clase, nivel de educación, posición económica o religión. La posibilidad de innovar, tanto individual como colectivamente, es un modo de superar el determinismo, de ser capaces de encontrar nuevas formas de vivir en comunidad y nuevos sentidos de futuro. Cuando una sociedad se propone salir del atraso, tiene que hacer uso de todo su potencial creativo e imaginativo para proponer alternativas originales de desarrollo. Por que la creatividad no sólo se aplica en el arte, sino también en el trabajo, el uso de las tecnologias, la política, la administración pública, la solución de los conflictos sociales. En resumen, es preciso abandonar la categorización binaria que opone "tradición" a "innovación". Ambos conceptos necesitan complementarse en un flujo que los enriquezca y permita combinaciones creativas acordes con la situación particular de cada grupo. 


\section{La realización de los derechos culturales en la diversidad}

A modo de conclusión, nos preguntamos cuál es el horizonte de realización de los derechos culturales en el actual contexto. Asi como la globalización implica un conjunto de riesgos que hemos intentado describir, también brinda oportunidades que el género humano deberá saber aprovechar con inteligencia. El ejercicio pleno de los derechos culturales, por lo tanto, se fundamentará en hacer cumplir ciertas pautas de acción, aprobadas por la comunidad internacional en la Conferencia Intergubernamental sobre Politicas Culturales para el Desarrollo, llevada a cabo en Estocolmo en 1998 (14).

- Reconocer la necesidad de prestar especial atención a la aplicación de instrumentos internacionales existentes sobre los derechos humanos, tales como la Declaración Universal de Derechos Humanos, el Pacto Internacional de Derechos Económicos, Sociales y Culturales y la Declaración y Acción de Viena, haciendo un inventario que permita identificar y valorar cada uno de los derechos culturales.

- Asegurar la participación plena de todos los ciudadanos y grupos en la vida cultural de las sociedades (paradigma de la democracia cultural), sin que sean discriminados por pertenecer a minorias o tener intereses y visiones diferentes a los de las clases predominantes, brindándoles las mismas oportunidades para realizarse plenamente.

- Diseñar y poner en práctica una política cultural nacional con una visión amplia, de acuerdo con las condiciones actuales del pais, animando la participación de todos los individuos, grupos y sectores sociales que conforman la sociedad civil.

- Alentar el compromiso de los medios masivos de comunicación con la promoción de las culturas y lenguas locales, regionales y nacionales (comprendidas las lenguas en peligro), la explotación y la promoción de la diversidad de las tradiciones cul- turales y de las identidades culturales nacionales e indígenas, garantizando su independencia de opinión.

Sumando estas acciones concretas a las que ya se vienen realizando en otros campos, tendremos la oportunidad de construir un mundo para todos, donde los derechos humanos nos hagan a todos iguales y, al mismo tiempo, nos permitan a todos ser diferentes.

Hay un poderoso mensaje en el libro La resistencia, de Ernesto Sábato:

A cada hora el poder del mundo se concentra y se globaliza. Veinte o treinta empresas, como un salvaje animal totalitario, lo tienen en sus garras. Continentes en la miseria junto a altos niveles tecnológicos. Posibilidades de vidas asombrosas a la par de millones de hombres desocupados, sin hogar, sin asistencia médica, sin educación. La masificación ha hecho estragos, ya es dificil encontrar originalidad en las personas $y$ un idéntico proceso se cumple en los pueblos. Es la llamada globalización (15).

Si se trata de globalización o mundialización, nuestra América tiene más experiencia que otras regiones del mundo. Cuando América tiene más experiencias que otras regiones del mundo. Cuando América surge en el mapamundi en el siglo XVI, se crea el concepto de economía-mundo. Sin América, el mundo estaba incompleto.

En procesos de globalización, nuestra América tiene una experiencia histórica acumulada que puede beneficiar al resto del mundo. Aquí se aprendieron idiomas nuevos. Aprendimos religiones nuevas. Adoramos dioses nuevos. Adaptamos y también exportamos cosas. Cuando hablamos de globalización, la experiencia civilizadora de América constituye un proceso excepcional. Ahora se trata de que esta experiencia siva para hacer frente al complejo mundo de hoy.

Edgar Montiel Jefe de la Sección Cultural y Desarrollo, UNESC, Paris 